\title{
Woman (Seated) with Tablet Computer
}

Contributor: Eli Blevis

$\rightarrow$ Curator/Editor: Eli Blevis

$\rightarrow$ Genre: Photographic minimalism, truth in (digital) photography

$\rightarrow$ Publication: Blevis, E. Pictorial: Qualities of focus.

Proc. of Creativity \& Cognition 2017. ACM Press (In press).

Is this deliberately out-of-focus image, recorded in the moment using a manual focus digital camera, more "truthful" than a sharply focused one edited using a postproduction tool such as Photoshop? Or does it tell a different truth that would otherwise remain hidden - that in our digital lives our screens can appear to loom larger than our bodies and dominate our physical presence? 